\title{
Screening of Antioxidant, Anti-tumor and Antimicrobial Herbal Drugs/Diets from Some Myanmar Traditional Herbs
}

\author{
M. M. Mon, S. S. Maw, and Z. K. Oo
}

\begin{abstract}
Fractions of ethanolic extracts of three kinds of Myanmar herbal plants were used to screen for their antioxidant, anti-tumor and antimicrobial activities in this study. Free radical scavenging activities were showed with EC50 values and $C$. hirsutus showed the best activity among them. Moreover, not only C. hirsutus but also A. japonica showed potential anti-tumor activity at $100 \mathrm{ppm}$ dosage according to results from bioassay with carrot dises infected with Agrobacterium tumefaciens after three weeks incubation at $28 \pm 2^{\circ} \mathrm{C}$. From the preliminary phytochemical and mineral analyses, the results showed absence of cyanogenic glycosides, lead $(\mathrm{Pb})$ and arsenic (As) in these plants and these plants are potentially safe to use as drugs or as diets. Although all kinds of plants extracts showed no toxicity by using in vitro brine shrimp larvae lethal toxicity test, A. japonica was selected to do further experiments as it has highest LC50 value among these three plants. In in vivo toxicity test with mice model, there is no toxic of A. japonica extract to the mice up to $2500 \mathrm{mg} / \mathrm{kg} / \mathrm{day}$ dosage indicating its safety for mammals. According to antagonistic activities against nine different species of food borne and human pathogenic microorganisms by the agar-well diffusion method, the methanol fraction of crude extract of the leaves of $A$. japonica showed most significant on the food borne pathogenic bacteria Shigella boydii and a zone of inhibition of $34 \mathrm{~mm}$ in diameter. Ethyl acetate fractions also showed best results against other pathogens. The MIC value was in the ranged from 0.625 to $5.0 \mathrm{mg} / \mathrm{ml}$ and the $\mathrm{MBC}$ value was in the ranged from 0.625 to $10.0 \mathrm{mg} / \mathrm{ml}$ for these tested microorganisms and this indicated the distinct growth inhibition and wider spectrum of their potential antimicrobial activity. Therefore, the research clearly indicates that these herbal plants of Myanmar's dry farm land are potentially advantageous for human health as herbal drugs/ diets or as herbal food preservative.
\end{abstract}

Index Terms-Antimicrobial Activity, Antioxidant Activity, Antitumor Activity, DPPH Free Radical.

\section{INTRODUCTION}

Oxygen is essential for aerobic forms of life, however oxygen metabolites are highly toxic. Under normal

Manuscript received July 10, 2011; revised June 29, 2011. This work was supported in part by the Department of Biotechnology, Mandalay Technological University under Ministry of Science and Technology, Republic of the Union of Myanmar.

M. M. Mon is with the Department of Biotechnology, Mandalay Technological University, Myanmar (phone: 95-2-57008; Fax: 95-2 57361; e-mail: myatmyat21@gmail.com).

S. S. Maw is with the Department of Biotechnology, Mandalay Technological University, Myanmar (e-mail: masawsandarmaw@ gmail.com).

Z. K. Oo is with the Department of Biotechnology, Technological University (Taungu), Myanmar (e-mail: zawkineoo08@gmail.com). conditions, the body is equipped with defense mechanisms that scavenge reactive oxygen species (ROS) or free radicals and protect the cell from oxidative damage. However, the detoxifying enzyme processes get overwhelmed, saturated and faulty under conditions of low dietary antioxidant intake, inflammation, aging or exposure to environmental factors such as irradiation or tobacco smoke, including some enzymes like cyclooxygenase-2 (COX-2), lipoxygenase (LOX) and inducible nitric acid synthase (iNOS) that generate intermediaries that damage cellular macromolecules including DNA and implied especially in the pathology physiology of numerous affections: atherosclerosis, heart failure, liver injury, ageing, chronic inflammation, neurodegenerative disorders, cancer, diabetes mellitus, and a plethora of other diseases. The brain is particularly very sensitive to oxidation stress possibly because of its high lipid content, high aerobic metabolic activity and low catalase activity [1].

Antioxidants (AOX) are considered a promising therapeutic approach as they may be playing neuroprotective (preventing apoptosis) and neurodegenerative roles. The main characteristic of an antioxidant is its ability to trap free radicals. In nature, AOX are grouped as exogenous or endogenous. The endogenous group includes enzymes (and trace elements part-of) like superoxidase dismutase (Zn, Mn and $\mathrm{Cu}$ ), glutathione peroxide (Se) and catalase, and proteins like albumin, transferrin, ceruloplasmin, metallothionein and haptoglobin. The most important exogenous AOX are dietary phytochemicals (such as polyphenols, quinones, flavonoids, catechins, coumarins, terpenoids) and the smaller molecules like ascorbic acid (Vitamin C), alpha- tocopherol (Vitamin-E) and beta-carotene Vitamin-E, and supplements. The antioxidant processes occur in cytosol, mitochondria or in plasma [2].

Currently available synthetic antioxidants like butylated hydroxyl anisole (BHA), butylated hydroxy toluene (BHT), tertiary butylated hydroquinone and gallic acid esters, have been suspected to cause or prompt negative health effects. Hence, strong restrictions have been placed on their application and there is a trend to substitute them with naturally occurring antioxidants. Recently there has been an upsurge of interest in the therapeutic potentials of medicinal plants as antioxidants in reducing such free-radical-induced tissue injury. Many plant extracts and phytochemicals have shown to have free radical scavenging properties but generally there is still a demand to find more information concerning the antioxidant potential of plant species $[3,4]$.

The aim of my research here is to study on the Myanmar 
traditional herbs that play a very important role in the development of new drugs. The objective of this research is to find out the potential antioxidant, anti-tumor and antimicrobial herbal drugs as well as food preservatives.

Medicinal plants are an important source of practical and inexpensive new drugs $[5,6]$. The results of preliminary phytochemical and chemical analysis reveal the presence of phenolic compounds and flavonoids in leaves of Ever green shrubs, Ardisia japonica Blume and Ageratum conyzoides L and ever green climber shrub Cocculus hirsutus (L) Diels plants, in this study described hereafter, the comparative antioxidant activity potential of the plant extracts were assessed against L-ascorbic acid (standard antioxidant) and tea extract (famous herbal antioxidant) using DPPH (1,1-diphenyl-2-picrylhydrazyl)[7,8]. Moreover, anti- tumor activities of plant extracts were also determined using Agrobacterium tumefaciens on carrot-disc assay [9, 10, 11]. The Ti-plasmid of $A$. tumefaciens causes the plant's cells to multiply rapidly without going through apoptosis, resulting in tumor formation similar in nucleic acid and histology to human and animal cancers.

The information presented here also illustrates the potential of the genus as a source of therapeutic agents for their antimicrobial activity. Herbal folk medicines provide an interesting and still largely unexplored source for drug development with potential chemotherapeutic benefits.

\section{MATERIALS AND METHODS}

\section{A. Collection, Storage and Preparation of Plant Materials}

Leaves of $A$. japonica, $A$. conyzoides and $C$. hirsutus were collected and dried in the shade at ambient temperature, and ground to powder before extraction. A known mass of each sample was then soaked in ethanol for 1 month. The extracts obtained were concentrated under vacuum at $60^{\circ} \mathrm{C}$ using a rotary evaporator to give the crude extracts of each plant. The dry extracts were stored in sealed vials in the refrigerator prior to further processes.

\section{B. Preparation of Plant Extract and Phytochemical and Mineral Analyses}

A known mass of each air dried leaves powder of $A$. japonica, A. conyzoides and $C$. hirsutus was soaked in ethanol for 1 month. The extracts obtained were then concentrated and stored in sealed vials in the refrigerator prior to further processes. Preliminary phytochemical examination of these plant extracts were analyzed by qualitative method. Ash and mineral contents were also determined quantitatively.

\section{Screening the Antioxidant Activity by using DPPH Free Radical}

\section{1) Dot-Blot DPPH Staining Assay}

Because of antioxidant compounds are frequently highly polar compounds, two polar: ethanol, methanol, as well as an extract of intermediate polarity: ethyl acetate and non-polar: n-hexane was selected. For the DPPH antioxidant assays and the Dot-Blot DPPH staining procedures, a final concentration of $10 \mathrm{mg} / \mathrm{ml}$ of each extract was prepared by re-dissolving the dried extract in acetone.

\section{2) 96-Multiwell Plate Assay}

Aliquots $0.5 \mathrm{ml}$ of $0.04 \mathrm{mM}$ DPPH solution in methanol was applied into each well of 96-multiwell plate. Aliquots $0.5 \mathrm{ml}$ (of a $50 \mathrm{mg} / \mathrm{ml}, 40 \mathrm{mg} / \mathrm{ml}, 30 \mathrm{mg} / \mathrm{ml}, 20 \mathrm{mg} / \mathrm{ml}$ and $10 \mathrm{mg} / \mathrm{ml}$ concentration) of each extract was then added immediately into each well except the well which was used as control. The sequence was also according to increasing quantity as shown in Fig: 3. Plates were allowed to dry for a few minute.

\section{Quantitative Determination of Antioxidant activity (In Vitro DPPH Free Radical Scavenging Assay)}

In this bioassay, $1 \mathrm{ml}$ of varying concentrations $(5,10,15$, 20 and $25 \mathrm{ug} / \mathrm{ml}$ ) of each sample extract was mixed with $2 \mathrm{ml}$ of $0.1 \mathrm{mM}$ DPPH(1,1-diphenyl-2-picryl hydrazyl radical) solution in methanol for $30 \mathrm{~min}$ in the dark at room temperature. Each test sample solutions were prepared as blank solutions when negative control was DPPH solution. L-ascorbic acid (Vitamin C) has been used as reference antioxidant and/or as positive control. Green tea extract was also used to study comparatively the antioxidant activity with the selected plant extracts. Absorbance was measured at $518 \mathrm{~nm}$ using spectrophotometer. Values obtained were converted to percentage antioxidant activity (AOXA\%). The antioxidant activity is expressed as effective concentration $\left(\mathrm{EC}_{50}\right)$ values, the concentration of the sample leading to $50 \%$ reduction of the initial DPPH concentration. The results are also expressed as the mg Vit-C equivalents per mg dry weight extract.

\section{E. Screening the Anti-tumor Activity by Carrot Disc Diffusion Bioassay}

Selected plant extracts were prepared with $100 \mathrm{ppm}$ and $1000 \mathrm{ppm}$ concentration. Carrot (Daucas carota L.) samples were sterilized with commercial bleach (cocorax) followed by washing with sterilized deionized water for three times. Each disc was diffused/overlaid with 100ul of Agrobacterium tumefaciens inoculums $\left(10^{8} \mathrm{cfumL}^{-1}\right)$. A $50 \mathrm{ul}$ aliquot of each extract with different concentration was then added using syringe into disc. Petri dishes were sealed by para-film and incubated at $30^{\circ} \mathrm{C}$. After 3 weeks, the discs were checked for young galls (tumors) developing from the meristematic tissue around the central vascular system.

\section{F. Estimation of the Natural Toxin of Crude Extracts by using Brine Shrimp Toxicity Test}

One gram of dried cysts of brine shrimp (Artemia salina) was hatched into free swimming forms. Each extract sample was prepared as $4000 \mathrm{ppm}, 2000 \mathrm{ppm}, 1000 \mathrm{ppm}, 800 \mathrm{ppm}$, $600 \mathrm{ppm}, 400 \mathrm{ppm}, 200 \mathrm{ppm}$ and 100ppm respectively. $2 \mathrm{ml}$ of each of the diluted extract solution was added to vials and 20 nauplii were collected with Pasteur pipette from the hatching container and were transferred to each vial carrying over the minimum amount of sea water. The vials with solvent and potassium dichromate solutions were also filled with 20 nauplii as controls. The vials were restored in the dark room while the temperature was controlled at $25 \pm 1^{\circ} \mathrm{C}$. After 6 hours and 24 hours incubation in the dark room, the vials were taken out for counting of nauplii. Counting of dead nauplii in each vial was made to get $\mathrm{LD}_{50}$ of acute toxicity (6hrs) and $\mathrm{LD}_{50}$ of chronic toxicity (24hrs) for plant ethanol 
extract. Nauplii were considered dead if they lay immobilized at the bottom of the vials [12].

\section{G. In vitro Mouse Model Toxicity Test}

Various concentrations of $A$. japonica crude extracts (500, $100,1500,2000$ and $2500 \mathrm{mg} / \mathrm{kg} /$ day) were dissolved in $20 \%$ ethanol in volume of $8 \mathrm{ml} / \mathrm{kg} /$ day. Either sex healthy mice weighed about $20 \mathrm{~g}$ with an age ranging between 4-6 weeks were kept in optimal experimental condition with free access to food and water and were observed for a period of 7days before use. Animal were housed in colony cages with covers. The animals were grouped into six having 5 mice in same sex in each group. One group was kept for solvent control, five groups for test plant. They received the test drug in the dose level ranging from 500 to $2500 \mathrm{mg} / \mathrm{kg} /$ day orally for six days. During administration of the drug, normal feed was given to animals; water was supplied freely. Observation was done for ten days and both dead and alive outcome of animals was daily recorded. The experiment was carried out following the rules and regulations for animal studies [13].

\section{H. Screening the Antimicrobial Activity by Agar-Well Diffusion Method}

All nine strains of food borne and human pathogenic microorganisms used in this study were as shown in Table2. Agar-Well diffusion test was used for testing the antimicrobial activity of crude extracts $[14,15]$.

Crude A. japonica extract was further separated using three solvents, n-hexane, ethyl acetate and methanol. For the antimicrobial test, sterile Muller-Hinton Agar for bacteria and Potato Dextrose Agar for fungi were used. With sterile technique, four of five similar colonies from the subculture of microorganisms were inoculated by swabbing thoroughly over the entire sterile agar surface of a plate to obtain a confluent lawn of microbial grow and equally spaced wells were made on the agar. Each test sample solution $(40 \mathrm{mg} /$ well $)$ was introduced with $50 \mu \mathrm{l}$ pipette into each well as labelled. The solvent only (70\% ethanol) was used as control. And then, the plates were placed in an incubator at $37^{\circ} \mathrm{C}$ for $22-24$ hour. After respective incubation time for microorganism, the plates were examined and the diameters of the zones of complete inhibition were measured to the nearest whole millimetre with a ruler.

\section{Determindation of MIC and MBC by Microdilution and Agar Diffusion Method}

The minimal inhibitory concentration (MIC) and the minimum bactericidal concentration (MBC) were applied to the aqueous extract that had proved to be highly effective against microorganisms by the broth microdilution and agardiffusion method. The aqueous extract of $A$. japonica was prepared with decreasing concentrations (from $20 \mathrm{mg} / \mathrm{ml}$ to $0.15625 \mathrm{mg} / \mathrm{ml}$ ) and placed in each test tube with different concentration. After that $1.0 \mathrm{ml}$ of adjusted inoculum to each test tube and all the tubes were incubated at $35-37^{\circ} \mathrm{C}$ from 16 to $20 \mathrm{hrs}$. MIC was taken as the most diluted concentration of antimicrobial remained sparkling clear and free of growth. After incubation of these tested samples diffused on respective agar media, MBC was taken as the most diluted range of concentration for no growth of the strains $[14,15]$.

\section{RESULTS AND DISCUSSION}

\section{A. Phytochemical and Mineral Analysis}

The phytochemical analysis of selected plant extracts had showed the presence of glycosides, flavonoids and phenolic compounds but had show the absence of cyanogenic glycosides. It has been mentioned that antioxidant activity of plants might be due to their phenolic compounds. Flavonoids are a group of polyphenolic compounds with known properties which include free radical scavenging, inhibition of hydrolytic and oxidative enzymes and anti-inflammatory action $[3,4]$. The presence of polyphenolic compound in the selected herbal plants prompted us to study the free radical scavenging activity. According to the results of mineral analysis, there is absence of lead and arsenic in the selected plants revealed that these plants are potentially safe for further activity test.

\section{B. Dot-Blot DPPH Staining Test}

The results of dot-blot assay showed colored spots where the aliquots of different fractions of each extract and/or different extracts, green tea $(C$. sinensis) extract and L-ascorbic acid (Vitamin-C) were dropped.

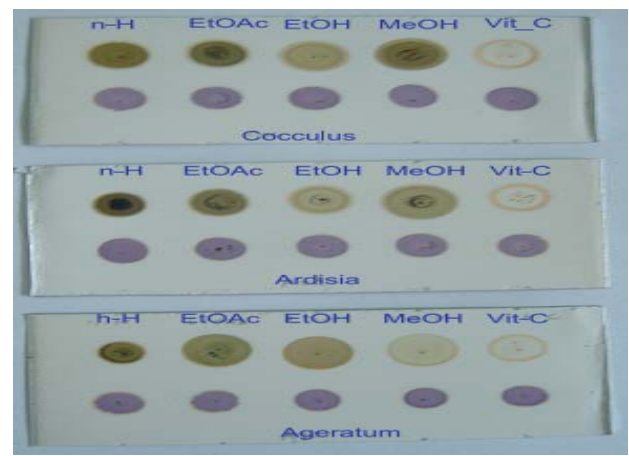

Fig.1. Scan of dot-blot test of a TLC Plate spotted with $0.4 \mathrm{mM} \mathrm{DPPH}$ solution in methanol after fractions of each extract (n-hexane fraction, ethyl acetate fraction, ethanol fraction, methanol fraction) and L-ascorbic acid (vitamin-C) was applied. Control is $0.4 \mathrm{mM}$ DPPH solution in methanol.

The purple area on the plate indicates no free radical scavenging (antioxidant) activity and the yellow area indicates free radical scavenger or antioxidant activity. The more intense the yellow colour, the greater the antioxidant activity is as shown in Fig- 1. The yellow colour can be masked by chlorophyll. These results indicate that all of the selected herbal plants (A. japonica, A. conyzoides and $C$. hirsutus) have potential antioxidant activity. It is extremely important to point out that, a strong correlation was observed between the radical scavenging capacity and polarity of the extracts. The more the polarity, the more the intense colour and the greater the antioxidant activity is.

\section{96-Multiwell Plate Assay}

The different extract's colour reactions with DPPH were measured by a multi-well plate reader and the result are as shown in Fig.2. Colour formation with DPPH is indicative of antioxidants in excess (and that the concentration of the plant extracts is too high, like top row in right hand side of Fig-4 (Vitamin-C) and pink of free radicals in excess (and that the concentration of the plant extracts is too low), like the first bottom row of right hand side of Fig-2 (Vit-C). Therefore a concentration range is sought where the yellow colour just 
disappears or becomes translucent before pink appears. The colour reaction shows a gradual change from purple to pink to yellow and indicates that the optimum concentration range has been reached.

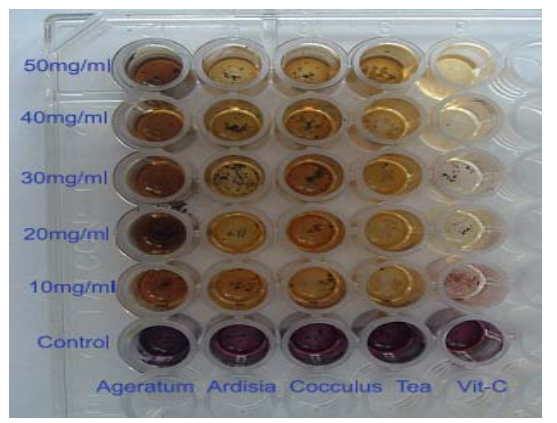

Fig.2. Part of 96 multi-well plate showing the gradually change in colour from deep purple to pink to yellow for comparative study of the antioxidant activities of each extract with that of black tea and vitamin-C at different concentrations after addition of $0.4 \mathrm{mMDPPH}$ solution in methanol.

\section{In vitro DPPH Free Radical Scavenging Assay}

$\mathrm{DPPH}$ radical is scavenged by antioxidants through the donation of proton forming the reduced DPPH[7, 8]. The color changes from deep purple to pink to yellow after reduction, which can be quantified by its decrease of absorbance at wavelength $518 \mathrm{~nm}$. Radical scavenging activity increased with increasing percentage of the free radical inhibition. The degree of discoloration indicates the free radical scavenging potentials of the sample/antioxidant by their hydrogen donating ability. The electrons become paired off and solution loses color stochiometrically depending on the number of electrons taken up.

Free radical scavenging activity of the selected plant extracts and extract of green tea and the standard antioxidant Vitamin-C are shown in Table 1.

TABLE 1. RADICAL SCAVENGING ACTIVITIES OF SELECTED EXTRACTS AND STANDARD ANTIOXIDANTS ON DPPH FREE RADICAL

\begin{tabular}{|c|c|c|c|}
\hline Sample & $\begin{array}{c}\mathrm{EC}_{50} \\
(\mathrm{ug} / \mathrm{ml}) \\
\text { mean } \\
\pm \mathrm{SD}\end{array}$ & $\begin{array}{c}\text { I\% or Free } \\
\text { Radical } \\
\text { Scavenging } \\
\text { Activity }(\%)\end{array}$ & $\begin{array}{l}\text { EC } 5 \text { Value } \\
\text { (mg equivalent } \\
\text { Vit-C/ mg dry } \\
\text { weight extract) }\end{array}$ \\
\hline Vitamin-C & $\begin{array}{c}8.31 \pm \\
0.33\end{array}$ & 61.49 & 1 \\
\hline C. hirsutus & $\begin{array}{c}10.68 \pm \\
0.81\end{array}$ & 55.06 & 0.77 \\
\hline $\begin{array}{c}11.70 \pm \\
\text { Tea } \text { C. sinensis })\end{array}$ & 0.37 & 53.61 & 0.71 \\
\hline A.japonica & $\begin{array}{c}12.72 \pm \\
0.02\end{array}$ & 53.84 & 0.65 \\
\hline A. conyzoides & $\begin{array}{c}15.19 \pm \\
0.11\end{array}$ & 50.56 & 0.55 \\
\hline
\end{tabular}

From this table, $\mathrm{EC}_{50}$ value of $C$. hirsutus extract shows less than that of $A$. japonica, A. conyzoides and green tea $(C$. sinensis) extracts. The results of free radical scavenging activity also showed that $C$. hirsutus have the strongest activity among the three plant extracts with $55.06 \%$ at $10.68 \mathrm{ug} / \mathrm{ml}$ (its $\mathrm{EC}_{50}$ value) concentration and first followed by Vit-C. Scavenging capacities of the $A$. japonica and green tea extracts have been found almost equal. $50 \%$ and above inhibition DPPH radical is considered as significant for scavenging activity.

Expressing plant extract's antioxidant activity in $\mathrm{mg}$
Vitamin $\mathrm{C}$ equivalent has the benefits that the antioxidant activity was quantified and different plant extracts were comparable. Compared to green tea where $1 \mathrm{mg}$ of dry weight, had Vitamin $\mathrm{C}$ equivalent of $0.71 \mathrm{mg}$ was a little lower than that of $C$. hirsutus, $0.77 \mathrm{mg}$. A. conyzoides and $A$. japonica showed almost half and over half of the value of antioxidant activity of Vitamin-C respectively. All selected plant extract here gave positive scavenging capacity (antioxidant activity) with DPPH as shown in Fig:3.

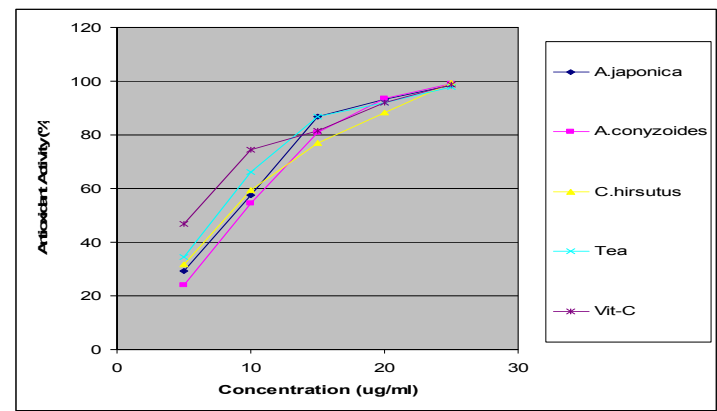

Fig.3. Antioxidant Activity (AOXA\%) of Selected Plant Extracts on DPPH Free Radical

\section{E. Anti-tumor Activity on Carrot-Disc Diffusion Bioassay}

A. tumefaciens is an indigenous soil bacterium known for its phytopathogenic effects. It causes crown gall tumor disease in a wide range of plants including most dicots, some monocots and some gymnosperms. Upon infection, the bacterium transfers part of its plasmid DNA to the plant. The Ti-plasmid causes the plant's cells to multiply rapidly without going through apoptosis, resulting in tumor formation similar in nucleic acid and histology to human and animal cancers. The T-DNA has also been transferred to human cells, demonstrating the diversity of insertion application. The mechanisms by which Agrobacterium inserts materials into human cells also by type IV system, is very similar to mechanisms used by animal pathogens to insert materials (usually proteins) into human cells also type IV secretion. This makes Agrobacterium an important topic of medical research as well. Besides, it plays a vital role in aspect of antitumor studies. After 3 weeks incubation of $A$. tumefaciens on each carrot disc in this research, negative control which use only for pathogenicity test showed young galls (tumors) developing from the meristematic tissue around the central vascular system.

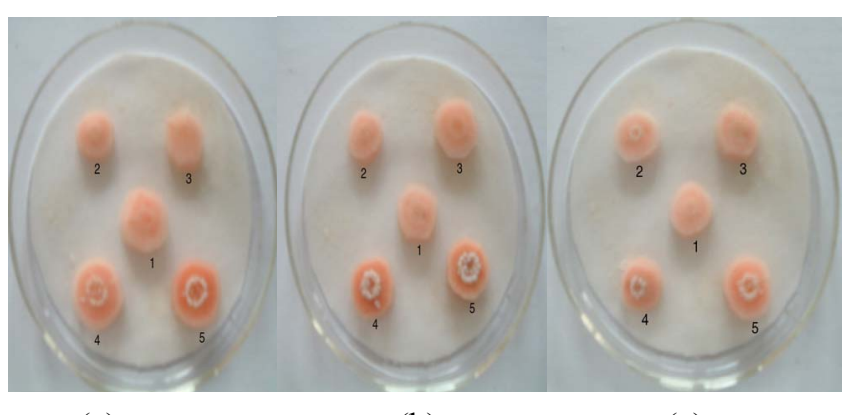

(a)

(b)

(c)

Figure.4 Anti-tumor Activity of sample extracts (a)Ardisia japonica (b) Cocculus hirsutus (c) Ageratum conyzoides on Carrot-disc Assay with Agrobacterium tumefaciens

(1) without any treatment (2) A. tumefaciens + sample extract (100 ppm)

(3) A. tumefaciens + sample extract $(1000 \mathrm{ppm})(4)(+) \mathrm{ve}$ control $(A$ tumefaciens $+70 \% \mathrm{EtOH})(5)(-) \mathrm{ve}$ control (A. tumefaciens) 
All extracts of selected plants showed anti-tumor activity. No gall was detected in carrot discs treated with 100ppm of $C$. hirsutus and A. japonica extracts and $1000 \mathrm{ppm}$ of $A$. conyzoides extract and the test results are shown in Fig.4 (a), (b) and (c). 70\% EtOH treated on the test disc was used in this case as positive control.

\section{F. In vitro Toxicity Testing using Brine Shrimp Larvae}

Toxicity of $A$. japonica was tested by using brine shrimp (Artemia salina) and the results are shown in Table2.

TABLE 2. MORTALITY OF BRINE SHRIMP LARVAE TO VARIOUS CONCENTRATION OF SELECTED HERBAL EXTRACT

\begin{tabular}{|c|c|c|}
\hline Extracts & $\begin{array}{c}\mathrm{LC}_{50} \text { (Acute } \\
\text { Toxicity- } \\
6 \mathrm{hrs} \text { exposure) } \\
\text { (ppm) }\end{array}$ & $\begin{array}{c}\mathrm{LC}_{50} \text { (Chronic Toxicity- } \\
24 \text { hrs exposure) } \\
\text { (ppm) }\end{array}$ \\
\hline A.japonica & $1572.33 \pm 3.7$ & $890.89 \pm 13.86$ \\
\hline $\begin{array}{c}\text { A.conyzoid } \\
\text { es }\end{array}$ & $2005.07 \pm 4.3$ & $768.72 \pm 16.02$ \\
\hline C.hirsutus & $2345.47 \pm 3.2$ & $587.04 \pm 15.08$ \\
\hline $\begin{array}{c}\text { Control } \\
\left(\mathrm{K}_{2} \mathrm{Cr}_{2} \mathrm{O}_{7}\right)\end{array}$ & $400 \pm 2.9$ & $11.69 \pm 0.16$ \\
\hline
\end{tabular}

From these results, it was found that $\mathrm{LC}_{50}$ values of all plants extracts were very much higher than that of potassium dichromate and it reveals the safety of these plants to use as herbal drugs.

\section{G. In vivo Toxicity Testing Method}

$\mathrm{LC}_{50}$ of oral administration of crude extract was essential to be investigated in rodent model before clinical trial was started [13]. According to the highest $\mathrm{LC}_{50}$ value of $A$. japonica among the three kinds of Myanmar herbal plants in in vitro assay, which plant was selected to do further researches.

In in vivo test, for acute and subacute toxicity, the crude extract of $A$. japonica was tested with serial doses of 2500 , $2000,15000,1000$ and $500 \mathrm{mg} / \mathrm{kg} /$ day given for six days. In this study, $\mathrm{LC}_{50}$ values of crude plant extract was found to be more than $2500 \mathrm{mg} / \mathrm{kg} /$ day. They were not toxic to the mice up to the highest concentration tested in this experiment, i.e., up to $2500 \mathrm{mg} / \mathrm{kg} /$ day. Antimicrobial Activity by Agar Well Diffusion Test, Tube Dilution Test and Plate Diffusion Test

Crude extract of $A$. japonica was further separated using three solvents (n-hexane, ethyl acetate and methanol). In this investigation, each fraction of ethanolic extracts $A$. japonica was screened against nine strains of pathogenic bacteria by using Agar Well Diffusion Method. Inhibition zone of diameter in millimeter was represented as the degree of activity. Antimicrobial activities of crude extracts of $A$. japonica are shown in Table 3.

According to the testing results, from those extracts, ethyl acetate fraction of crude extract shows best activity against Staphylococcus aureus (18mm), Bacillus cereus (29mm), Pseudomonas aeruginosa (18mm), Penicilli-um marneffei $(19 \mathrm{~mm})$, and Salmonella typhi $(17 \mathrm{~mm})$ in inhibition zone diameter respectively. Methanol fraction of crude extracts showed good activity against Escherichia coli (16mm), Shigella boydii $(34 \mathrm{~mm})$ and $\mathrm{n}$-hexane fraction also showed good activity against Shigella Sonnei (12mm). Although positive control Ampicillin didn't show activity against Vibrio cholare, all fractions of crude extract showed activity.
Therefore, the crude extract was used to determine the MIC (Minimal Inhibitory Concentration) against nine strains of pathogenic microorganisms by tube dilution test. MIC and MBC (Minimum Bactericidal Concentration) values of crude extracts against tested microorganisms are also showed in this Table.

TABle3. ANTIMICROBIAL ACTIVITY OF CRUDE A. JAPONICA PlantS EXTRACTS ON THE TESTED MICROORGANISMS

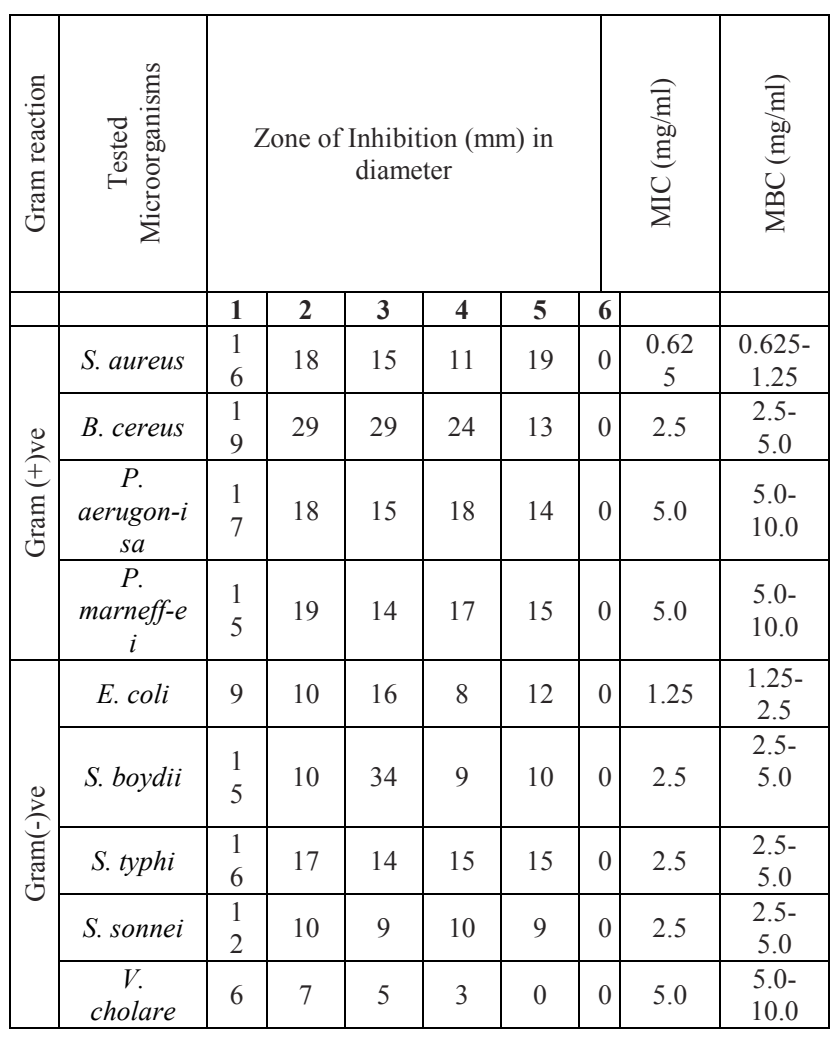

1.n-hexane fraction; 2.Ethyl acetate fraction;

3.methanol fraction; 4.crude extract;

5. $(+)$ ve control (Ampicillin 50ug/well)

6. (-)ve control $(70 \% \mathrm{EtOH})$;

\#Concentration of each extracted sample- $40 \mathrm{mg} / 50 \mu \mathrm{l}$ per Well

The MIC values of $A$. japonica against tested microorganisms are in the ranged from 0.625 to $5.0 \mathrm{mg} / \mathrm{ml}$ and $\mathrm{MBC}$ values are in the ranged from 1.25 to $10.0 \mathrm{mg} / \mathrm{ml}$ respectively. This indicated the distinct growth inhibition and wider spectrum of its potential antimicrobial activity.

\section{CONCLUSIONS}

Plants have long provided mankind with a source of medicinal agents, with natural products once serving as source of all drugs. Though synthetic chemical also have long been used as active agents in reducing the incidence of plant, animal and human diseases, they are costly, have potentially harmful effect on the environment and may induce pathogen resistance. Thus, biological controls or the use of microorganisms or their secretions to prevent diseases offer an attractive alternative or supplement to disease management without the negative impact of chemical control. Therefore, recently, much attention has been directed toward extracts and biologically active compounds isolated from popular plant species. The use of medicinal plants plays a vital role in covering the basic health needs in developing countries. 
According to the results from the phytochemical and mineral analyses, cyanogenic glycoside, lead and arsenic was not detected in all selected plants such as .A. japonica, $A$. conyzoides and $C$. hirsutus in this research. So, we can assume that these plants are safe to use as medicinal plants. From this study we can conclude that all of these three herbal plants can be used as the source of typical diet or drugs of antioxidant and anti-tumor activity as having the potential to reduce disease risk especially $C$. hirsutus and A. japonica can be used as potential antioxidant and antitumor herbal drugs. Most of antioxidant compounds in a typical diet are derived from plant sources and belong to various classes of compounds with a wide variety of physical and chemical properties.

Moreover, the traditional use of $A$. japonica plant for the treatment of microbial infectious diseases, mainly against bacteria is promising. Effective extracts could provide potential leads towards the development of novel and environmental friendly biologically active agents.

\section{ACKNOWLEDGEMENT}

I wish to express my profound gratitude to Ministry of Science and Technology for encouraging to performed researches. The author would also like to express her appreciation and thanks to Dr. Mya Mya Oo, Rector of Yangon Technological University and Mandalay Technological University for her supporting the facilities through out the research. Moreover, the author would also like to express her appreciation and thanks to her beloved parents, eldest and younger sisters and her close friends for their invaluable suggestions and their kind help through this work.

\section{REFERENCES}

[1] B. Halliwell, J. M. C. Gutteridge. "Free radicals in biology and medicine", Oxford University Press, UK, 2007.

[2] S. Foley, S. Navaratnam, D.J. McGarvey, E. J. Land, and T.G. Truscott, "Singlet oxygen quenching and the redox properties of hydroxycinnamic acids", Free Radical Biol. Med, 1999, 26, 1202-1208.

[3] T. Hanto, H. Kagawa, T. Yasuhara, and T. Okuda, "Two new flavonoids and other constituents in licorice root: their relative astringency and radical scavenging effects", Chem. Pharm. Bull., 1988. 36: 1090-2097.

[4] N. C. Cook, S. Samman, "Flavonoids: chemistry, metabolism, cardio protective effects, and dietary sources". J. Nutr. Biochem.1996, 7, $66-76$
[5] Anonymous, "The wealth of India, a dictionary of Indian raw materials and industrial products", New Delhi, Raw Materials, Vol.1, (1948).

[6] K. Soe, and T. M. Ngwe, "Medicinal plants of Myanmar, identification and uses of some 100 commonly used species", Series 1 , Published by Forest Resource Environmental Development and Conservation Association (FRDA), 1st editon, (2004).

[7] P. Molyneux, "The use of the stable free radical diphenyl picryl hydrazyl (DPPH) for estimating antioxidant activity", Songklanakarin J Sci Technol.2004, 26(2):211-219.W.-K.

[8] M. Oktay, I. Gulein, and I. Kufreviolglu, "Determination in vitro antioxidant activity of fennel (Foeniculum vulgare) seed extracts, Labenson-Wiss U. Technol.2003; 36:263-71

[9] A. B. Galsky,J. P. Wilsey, R. G. Powell. "Crown-gall tumor disc bioassay: a possible aid in the detection of compounds with antitumor activity". Plant Physiol 65: 184Đ185, 1980.

[10] F. C. Chen, S. H. Hseu, S. T. Hung, M. C. Chen, and C. Y. Lin, "Leaf, stem and crown galls on perennial asters caused by Agrobacterium tumefaciens in Taiwan", Bot. Bull. Acad. Sin. (1999) 40: 237-242

[11] A.C. Braun, "The relevance of plant tumor systems to an understanding of the basic cellular mechanisms under lying tumorigenesis", Progress in Expermimental Tumor Research, 1972, 15:165-187.

[12] B. N. Meyer, N. R. Ferrrigni, J. E. Putnam et al. "Brine shrimp: a convenient general bioassay for active plant constituents". Planta Med 45: 31-34, 1982.

[13] T. J. Birdi, S. Brijesh, and P. G. Daswani, "Approaches towards the preclinical testing and standardization of medicinal plants", Foundation for Medicinal Research, India, (2006).

[14] A. Rojas, L. Hernandez, R. P. Miranda, and R. Mata, "Screening for antimicrobial activity of crude drug extracts and pure natural products from Mexican medicinal plants, J. Ethanopharmacol, 1992, 35-275-83.

[15] D. Thangadural, M. B. Viswanathan, and N. Ramesh, "Indigoferabietone, a novel abletane diterpenoid from indigofera longeracemosa with potential antituberculous and antibacterial activity, Pharmazie (2002); 57:714-15.

M.M. Mon was born at Kanma Township, Thayet District, Magway Region, Republic of the Union of Myanmar at 21st Jan 1971. Her 1st and 2nd degrees are B.Sc (Hons:) Chemistry, Yangon University and M.S. (Engineering Chemistry), Yangon Technological University, Myanmar. She had finished her doctoral degree with Engineering Chemistry major since 2003 from Yangon Technological University, Myanmar.

Dr. Mon is a LECTURER from Department of Biotechnology, Mandalay Technological University, Myanmar. Two of her papers were registered at ICSE2009 at 2-3 December 2009 and the other one was registered at NCSE2011 at 27-29July 2011 and the next one was registered at ICBET2011at 17-19 June 2011. She is doing some researches related with medical biotechnology and environmental biotechnology with her colleague and/ or with her candidates. She is also one of the boards - of - examiners at Mandalay Technological University for Biotechnology Specialization. 